OPEN ACCESS

Edited by:

Filippo Maggi,

University of Camerino, Italy

Reviewed by:

Marcus Carl Stensmyr

Lund University, Sweden

Angel Guerrero,

Instituto de Química Avanzada de

Cataluña (IQAC), Spain

Mohammad Reza Youssefi,

Islamic Azad University, Babol, Iran

*Correspondence: Antonios Michaelakis

a.michaelakis@bpi.gr

Serkos A. Haroutounian sehar@aua.gr

Specialty section:

This article was submitted to

Chemical Ecology,

a section of the journal

Frontiers in Ecology and Evolution

Received: 05 September 2018 Accepted: 14 November 2018 Published: 29 November 2018

Citation:

Evergetis $E$, Bellini R, Balatsos $G$, Michaelakis A, Carrieri M, Veronesi $R$,

Papachristos DP, Puggioli A,

Kapsaski-Kanelli V-N and

Haroutounian SA (2018) From Bio-Prospecting to Field Assessment: The Case of Carvacrol Rich Essential

Oil as a Potent Mosquito Larvicidal and Repellent Agent.

Front. Ecol. Evol. 6:204. doi: 10.3389/fevo.2018.00204

\section{From Bio-Prospecting to Field Assessment: The Case of Carvacrol Rich Essential Oil as a Potent Mosquito Larvicidal and Repellent Agent}

\author{
Epameinondas Evergetis ${ }^{1}$, Romeo Bellini ${ }^{2}$, George Balatsos ${ }^{3}$, Antonios Michaelakis ${ }^{3 *}$, \\ Marco Carrieri ${ }^{2}$, Rodolfo Veronesi ${ }^{2}$, Dimitrios P. Papachristos ${ }^{3}$, Arianna Puggioli ${ }^{2}$, \\ Vassiliki-Nafsika Kapsaski-Kanelli ${ }^{1}$ and Serkos A. Haroutounian ${ }^{1 *}$ \\ ${ }^{1}$ Faculty of Animal Sciences and Aquaculture, Agricultural University of Athens, Athens, Greece, ${ }^{2}$ Centro Agricoltura \\ Ambiente "G. Nicoli," Crevalcore, Italy, ${ }^{3}$ Department of Entomology and Agricultural Zoology, Benaki Phytopathological \\ Institute, Kifissia, Greece
}

Contemporary legislation tends to increase limitation on the use of all synthetic pesticides, promoting bio-pesticides as a safer alternative. Bio-prospecting efforts for bio-pesticides provide results, which rarely reach the industry. Present essay elaborates on our efforts to chart the path from the laboratory bench to field assessment. Eight Mediterranean wild gathered foods provided the essential oils that were assessed as mosquito control agents against the Asian tiger mosquito (Aedes albopictus). Three Lamiaceae essential oils, derived from Satureja thymbra, Origanum onites, and Thymbra spicata presented carvacrol as principal component. All exhibited DEET-like repellent performance and total larvae mortality defining the carvacrol rich essential oil (CREO) as a promising mosquito control agent. A commercial variety of Origanum vulgare ssp. hirtum, was selected as CREO source and subjected to dose-response and eco-toxicity studies. We have found significant larvicidal (LC90 of $58,747 \mathrm{mg} / \mathrm{L})$, and repellent $\left(0.2 \mu \mathrm{L} / \mathrm{cm}^{2}\right)$ properties, but also severe toxicity ( $\left(\mathrm{C}_{90}\right.$ of $12,806 \mathrm{mg} / \mathrm{L}$ ) against Macrocyclops albidus. This last figure was the limit for the larvicidal field assessment; while for the repellent evaluation was used double the minimum indication $\left(0.4 \mu \mathrm{L} / \mathrm{cm}^{2}\right)$. CREO was tested per se as larvicidal agent, and emulsified for both repellent and larvicidal field activity. The emulsified CREO's spatial repellent assessment showed maximum efficacy of $86 \%$ in day 1 that gradually declined in the following 2 days $(81 \%, 69 \%)$. Both emulsified and crude CREO proved to be efficient larvicidal agents, with crude CREO (3 weeks) overrunning slightly the emulsified (2 weeks) in terms of endurance. Conclusively, CREO in its emulsified form may be considered as a promising mosquito larvicidal and repellent agent, applicable in both precautionary and emergency response measures.

Keywords: carvacrol, mosquito, aedes, larvicidal, repellent, field assessment, essential oil 


\section{INTRODUCTION}

Bio-pesticides emerge as a viable alternative for insect control because of their conformity with organic agriculture limitations and the consumers' trend for natural solutions. Recently published data reveal an average decrease by $78 \%$ of insects during the last 24 years (Vogel, 2017). This decline is mainly attributed to the extensive use of pesticides, applied both for agricultural and public health purposes (Vogel, 2017). The impacts from insects decline may be enhanced by the ongoing climate change (Pires et al., 2018), and globalization that facilitates the species migration. Among these impacts, our work focused on the expansion of alien invasive species, which translates to significant pressures on public health and biodiversity conservation. Among the numerous invasive invertebrates, mosquitoes have been identified as a major public health threat.

A recent review (Sands et al., 2016) on viral infection outbreaks and pandemics indicated that from the 12 events accounted during the twenty-first century five involved mosquitoes as vectors of Zika and Chikungunya viruses. This fact has pinned mosquito control as a primary target of the World's Health Organization (WHO) in order to mitigate future infectious diseases outbreaks (WHO, 2016). The majority of the first response measures, currently applied in mosquito control, implicate the use of insecticides in combination with personal protection means (Loh and Yap, 1989; Kroeger et al., 2006). The utilization of synthetic insecticides is facing severe restriction because of their adverse effects and resistance development (Morrison et al., 2008). In this context, several alternative mosquito control means have been developed, including the utilization of bacteria such as Bacillus thuringiensis israelensis, Lysinibacillus (Bacillus) sphaericus or sterile male mosquitoes (Lees et al., 2015; Zhang et al., 2015). Most of these methods are oriented to function as preventive and not first response measures. Viral infections outbreak though, do occur and demand the development of effective mosquito control agents for first response application.

Bio-prospecting for natural biocides indicates that Essential Oil (EO) constitute a promising source of bio-pesticides. The consideration of EO as mosquito control agents is advocated through conformity with consumers' demands, but most importantly through their environmental performance. EOs are biodegradable, exhibiting limited ecosystem persistence and bioaccumulation. In addition, EOs have been co-evolved with plant pollinators, therefore encompassing a compatibility that minimizes their adverse effects. As a result EOs have been utilized as active ingredients in commercial products. The EOs of citronella (Kongkaew et al., 2011) and tea tree (Ramadass and Thiagarajan, 2015) are used in repellents directly applicable on human skin, for the production of protective garments and nets (Enayati and Hemingway, 2010), as open space repellents in aromatic candles (Müller et al., 2009), and surface cover sprays (WHO, 2006). Surprisingly, the equally documented larvicidal properties of EOs (Evergetis et al., 2012) remain commercially unexploited. An explanation for this discrepancy is provided by a critical review on mosquito control research (Chellappandian et al., 2018) that proposed the lack of field assessment results as the main handicap for the larvicidal EOs uptake.

The aforementioned constraints and limitations on the development of bio-pesticides were placed in the core of the herein presented study. Between bio-prospecting and field assessment we introduced an intermediate stage aiming to facilitate the up-scaling of the laboratory experiments. The inclusion of this intermediate stage employed three main tasks targeting; the delineation of eco-toxicity; the definitions of the optimum concentration, and formulation. This prioritization enabled resolution of conflicts relating to the selection of the field assessment parcels, and the expected environmental impacts of the bio-pesticides. In this context we present herein field assessment results for mosquito larvicidal and/or repellent agents, which are prerequisites for inclusion in WHO's toolbox against infectious diseases (WHO, 2005). The integrated approach we propose may be perceived as a handy, from cradle to market, roadmap for the development of bio-pesticides. It must be noted, though, that the institutional structure of the team was the most crucial factor for the flawless implementation of the experiments. Specifically, the inclusion of academic, research, and local authorities facilitated the study's progress, enabling the wise selection of experimental parcels, and prompt implementation of field experiments, within the urban grid of Bologna, Italy.

\section{MATERIALS AND METHODS}

\section{Bio-prospecting \\ Plant Material}

The initial biodiversity sampling was performed through the selection of the appropriate culinary herbs. From 2012 to 2014 two Greek indigenous aromatic herbs and six shrubs were collected from various locations and habitats of Greece: Vitex agnus-castus L. (common: Monk's Pepper), Ruta chalepensis L. (common: Fringed Rue), Origanum onites L. (common: Rígani), Foeniculum vulgare Mill. (common: Fennel), Satureja thymbra L. (common: Savory), Echinophora tenuifolia ssp. sibthorpiana (Guss.) Tutin (common: Cortuk), Salvia fruticosa Mill. (common: Greek Sage), and Thymbra capitata (L.) Cav. (common: Conehead Thyme). Collection details of all herbal taxa are included in Table 1. All taxa were identified through Flora Europaea (Tutin et al., 2013) taxonomical keys and the resulting nomenclature was updated through (The Plant List, 2013). A voucher specimen for each plant sampled is deposited in the herbarium of the Agricultural University of Athens, Athens, Greece.

\section{Essential Oils Isolation and Analyses}

All EOs were obtained by hydro-distillation using a modified Clevenger apparatus, according to previously described procedure (Evergetis et al., 2016). In addition the EO from Echinophora tenuifolia ssp. sibthorpiana (Guss.) Tutin, was obtained by acidic hydro-distillation (ETa). The isolation yields of all EOs are included in Table 1. The chemical composition of EOs was determined on a gas chromatographer (GC) coupled to a mass spectrometer (MS) in accordance with a previously 
TABLE 1 | Bio prospected taxa; collection location and dates; and essential Oil yield of the herbal material.

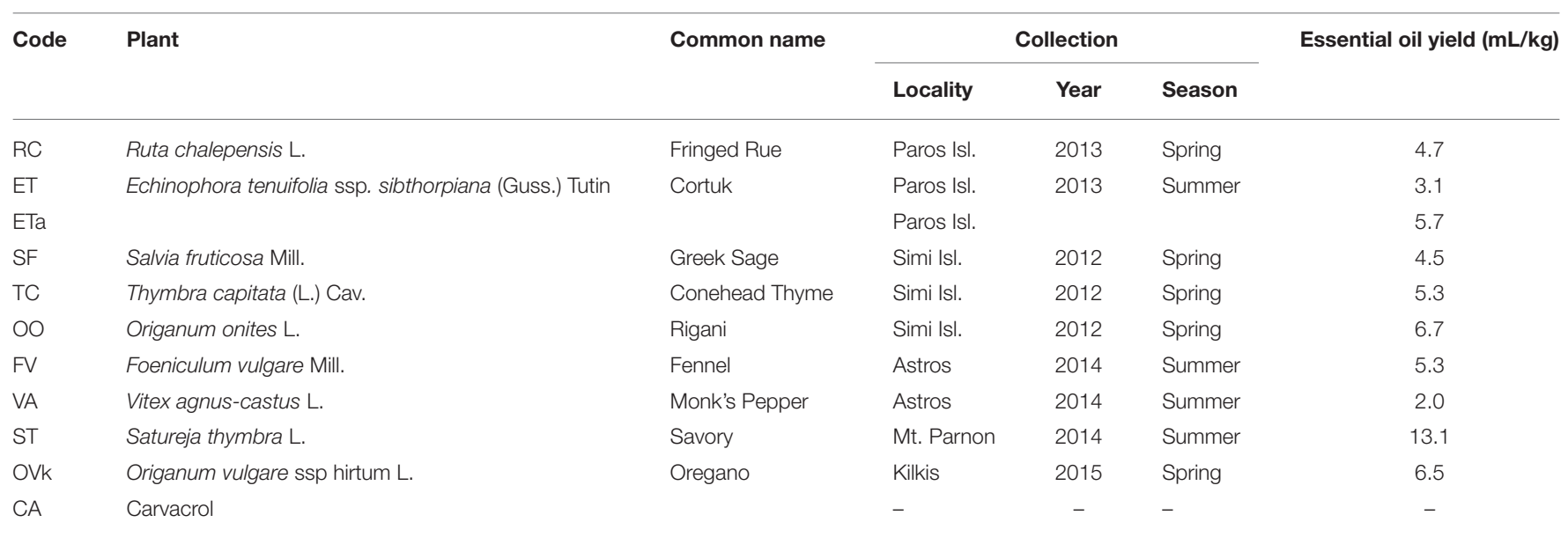

described method (Evergetis et al., 2016). Mass spectra were compared with NIST 11 and Willey 275 databases and authentic samples where available.

\section{Mosquitoes Rearing}

The adult females of Aedes albopictus used in the bioassays were obtained from a colony maintained in the Benaki Phytopathological Institute (Kifissia, Greece), according to previously described protocols (Giatropoulos et al., 2012).

\section{Repellent and Larvicidal Bioassays}

The assessments of the repellent properties were based on the human landing counts explicitly described in previous studies (Giatropoulos et al., 2012; Govere and Durrheim, 2015). The larval mortality bioassays were carried out according to a modified version of the test method for larval susceptibility recommended by WHO (2005) and also explained in previous studies (Giatropoulos et al., 2012; Govere and Durrheim, 2015).

\section{Up-scale}

\section{Field Assessment EO, Chemicals and Standards}

After the preliminary evaluation, in laboratory scale, of the abovementioned taxa a targeted sampling was performed during 2015 for the determination of a commonly available taxon capable to produce CREO. For this purpose, a commercial variety of the most active EO (Origanum) was selected, namely the Origanum vulgare ssp hirtum. The latter was obtained from Ecopharm Hellas S.A., Greece and produced the oregano EO (OVk) that was used for the performance of dose response, ecotoxicity experiments and field tests. Analytical grade carvacrol $(96 \%)$ and TWEEN $^{\circledR} 20$ (97\%) were obtained from Sigma Aldrich (Steinheim, Germany). The first was utilized as a reference standard during the second set of bioassays, and the second as emulsifying agent in the field assessments. DEET $(N, N$ Diethyl-3-methylbenzamide) and dimethyl sulfoxide (DMSO) were also purchased from Sigma-Aldrich.

\section{Non-target Insects Rearing}

The adults of Macrocyclops albidus (Copepoda, Cyclopidae) used for the laboratory mortality bioassays were obtained from the rearing unit of the Laboratory of the Medical and Veterinary Entomology Department, Center Agriculture and Environment “G. Nicoli" (Veronesi et al., 2015).

\section{Laboratory Mortality Bioassays On Non-target Organisms}

The mortality bioassays against the non-target species $M$. albidus were carried out in accordance with a modified version of the recommended by WHO test method for larval susceptibility (WHO, 2005). Specifically, for each of the two tested products (oregano EO and carvacrol), different concentrations were tested (solutions of $1,4,16$, and $64 \mathrm{mg} / \mathrm{L}$ ) using clean $330 \mathrm{~mL}$ glasses filled with $100 \mathrm{~mL}$ of each solution. For each dose four replications were tested with 20 adult individuals in each glass. To reduce cannibalism copepods were fed ad libitum with young Ae. albopictus larvae until the day of treatment. The solutions were prepared by transferring the corresponding amounts of each compound to a vial and the solvent was removed. Stock solutions of oregano EO and carvacrol were prepared by using DMSO. Laboratory procedure was adopted to guarantee homogeneous $1 \%$ DMSO in the final glasses together with the EOs tested doses. Four glasses, each with 20 copepods were also settled as control with $1 \%$ aqueous solution of DMSO. In total 16 glasses with 320 copepods were set up for each testing products while four glasses with 80 copepods were used as a control. The glasses were randomly placed in a climatic chamber maintained at $28 \pm 1^{\circ} \mathrm{C}$ on a 14:10 L:D cycle. At $24 \mathrm{~h}$ post-treatment the glasses were examined by visual observations for copepod mortality. In case the mortality registered in the control resulted values $>0.0 \%$, the bioassay was repeated.

\section{Field Assessment}

\section{Field Test for Evaluation of the Spatial Repellent Efficacy}

The field trial was performed in two highly vegetated urban areas, each occupying $50 \times 15 \mathrm{~m}$ space of a public garden of Bologna, during the second week of July when the Ae. albopictus population achieves its peak of density. The day two and one before the treatment human landing collection (HLC) were 
conducted by four expert operators using manual aspirators, during the maximum female activity (about 5-7 PM). HLC sessions of $30 \mathrm{~min}$ each were implemented within the treated and the control areas. Operators were rotated every day to avoid possible bias. Collected mosquitoes were released back after each session. The tested product was distributed taking care to spray homogeneously both grass and vegetation up to $3 \mathrm{~m}$ height, covering completely the test area of $50 \times 10 \mathrm{~m}$. The respective control area was sprayed with the same volume of water solution containing only $5 \%$ of TWEEN ${ }^{\circledR} 20$. The treatment was performed on July 12,2017 at 6.00 PM. Area A was sprayed using a manual rotator Volpi (Casalromano, Mantova, Italy), with $10 \mathrm{~L}$ of solution containing 5\% TWEEN ${ }^{\circledR} 20$ and $4 \%$ oregano EO, whereas area B was sprayed with the same volume of water solution containing 5\% TWEEN ${ }^{\circledR} 20$.

\section{Field Testing of Mosquito Larvicidal and Repellency Efficacy in Catch Basins}

The trial was conducted in the urban area of Crevalcore (Italy), during the period July 13- August 3, by randomly selecting 15 catch basins colonized by mosquito larvae, from which 5 were treated with $10 \mathrm{ml}$ oregano EO 100\%; 5 with $10 \mathrm{~mL}$ oregano EO $100 \%+10 \mathrm{~mL}$ TWEEN ${ }^{\circledR} 20$, diluted in $40 \mathrm{~mL}$ water; and 5 left untreated as a control. The mosquito larvae sampling was conducted using an aquarium water net, immediately before the treatment, $48 \mathrm{~h}$ post-treatment and 7, 14, 21 days post-treatment. Larvae and pupae were counted in respect their species and age. This test tried to measure the direct larvicidal activity along with the possible repellency on ovipositing females. During each sampling were recorded: time of the day, water and air temperature, and rainfall during the trial.

\section{Data Analysis}

Data concerning the adult repellency (mosquito landings) and larval toxicity (percentage larval mortality) for the essential oils of each plant were analyzed using Kruskal-Wallis test. When significant differences were detected, Mann-Whitney $U$-test were carried out for pair-wise comparison (SPSS 21.0). Mosquito and non-target dose response bioassays mortality data were analyzed by probit regression analysis using POLO-PC (LeOra Software POLO-PC, Berkeley, CA, U.S.A.) and SPSS 21.0.

Repellent efficacy was calculated using the formula of Mulla et al. (1971), which takes into account natural changes in the mosquito populations in both treated and untreated areas:

$$
\% \mathrm{R}=1-[(\mathrm{C} 1 \times \mathrm{T} 2) /(\mathrm{T} 1 \times \mathrm{C} 2)](\text { expressedasapercentage })
$$

Where $\mathrm{C} 1$ is the number of adults collected in the untreated area during pre-treatment; $\mathrm{C} 2$ the number of females collected in the untreated area during post-treatment; T1 the mean female density in the treated area during pre-treatment; and T2 the mean female density in the treated area during post-treatment. For the mosquito larvicidal and repellency efficacy in catch basins, the average of larval density was analyzed by ANOVA. The Duncan Test was used as the post ad hoc comparison to identify differences between pairs.

\section{RESULTS AND DISCUSSION \\ Bio-prospecting \\ Essential Oil Analysis}

In total 52 phytochemicals were identified, accounting from 94 to $99 \%$ of the 9 EOs studied, and are presented in Table 2, along with the respective percentage of occurrence in each EO. Thirteen phytochemicals exceeded the 10\% margin and were considered as major compounds. Among them are included two cyclic monoterpenes: $\alpha$-phellandrene, and $\gamma$ terpinene; Three bicyclic monoterpenes: sabinene, $\beta$-pinene, and $\delta$-3-carene; eight oxygenated molecules: the monoterpenes eucalyptol, D-fenchone, 2-nonanone, and 2-undecanone; and the aromatic compounds estragole, carvacrol, $p$-cymene, and methyl eugenol. These results agree with previous studies regarding the investigated taxa EOs composition. Thus, Fringed Rue is known to contain as major compounds the aliphatic ketones 2nonanone, and 2-undecanone (Perestrelo et al., 2016); Monk's Pepper has been reported to contain eucalyptol as major compound (Senatore et al., 1996); Conehead Thyme, Rigani, and Savory have been found to contain carvacrol as major compound (Economou et al., 2014); Fennel to contain estragole and Dfenchone as prominent phytochemicals (Rather et al., 2016); Greek Sage to contain $\beta$-pinene and eucalyptol as prevailing compounds (Ali et al., 2013); Cortuk to contain methyl eugenol, $\alpha$-phellandrene, and $p$-cymene as leading compounds (Baser et al., 1994).

\section{Repellent Bioassay}

The repellent assessment indicates that four EOs, derived from Greek Sage, Conehead Thyme, Rigani and Savory, showed an efficacy similar to DEET through the achievement of zero landings over $5 \mathrm{~min}$ of exposure in the bioassay's course. Another EO derived from Cortuk's conventional distillation presented only 0.13 landings, whereas Cortuk's acidic distillation and Monk's Pepper EOs were also considered highly efficient repellents since their application concluded with 0.88 and 1.25 landings over $5 \mathrm{~min}$ of exposure. Finally, Fennel and Fringed Rue EOs presented high to moderate repellence indicated by the respective numbers of 3.5 and 11.13 landings. The repellent bioassay results are presented cumulatively in Table 3.

Among the eight taxa assessed for their EOs repellent potentials, Conehead Thyme and Cortuk had never been evaluated before against any insect species. Also, limited results not referring to the target organisms of the present study were noticed for Savory, and Greek Sage repellent activity. Rigani EO presented only one previous assessment as Cx. pipiens repellent that matched present results (Carroll et al., 2017). Finally, Fringed Rue, Monk's Pepper and Fennel EOs, have been extensively studied as repellents against numerous mosquito species, including at least one Aedes species. Fennel EO has been recorded as an efficient repellent against $C x$. pipiens (Traboulsi et al., 2005), but has been found of moderate repellence against Ae. aegypti (Kim et al., 2002; Choochote et al., 2007). Monk's Pepper EO was also evaluated as a repellent against Ae. aegypti (Semmler et al., 2009, 2014), and Cx. quinquefasciatus (Semmler et al., 2014) being found in both cases of insignificant efficacy. 
TABLE 2 | Essential oils analyses.

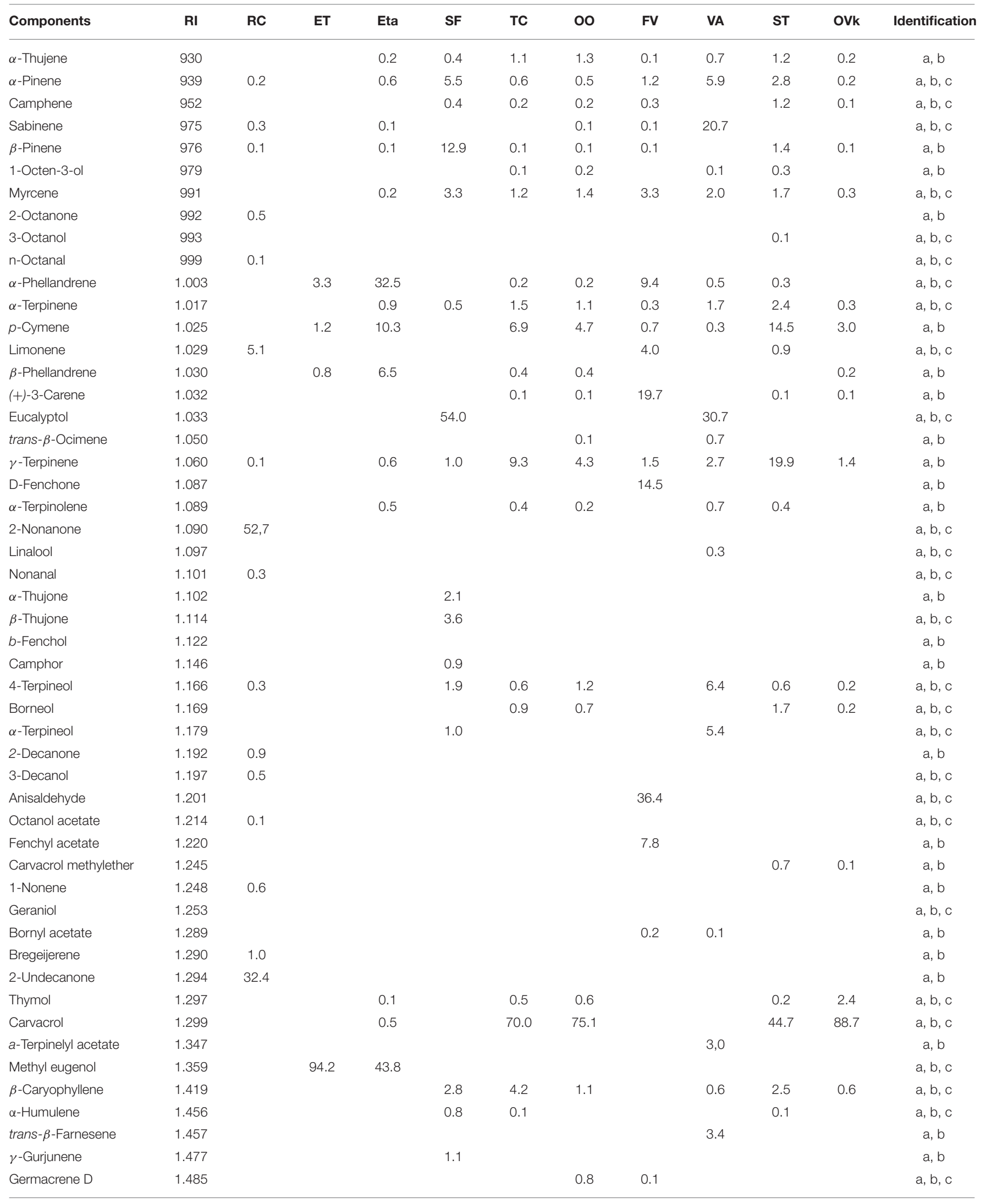


TABLE 2 | Continued

\begin{tabular}{|c|c|c|c|c|c|c|c|c|c|c|c|c|}
\hline Components & $\mathbf{R I}$ & RC & ET & Eta & SF & TC & OO & FV & VA & ST & OVk & Identification \\
\hline Bicyclogermacrene & 1.500 & & & & & & 0.6 & & 3.7 & & & $a, b$ \\
\hline$\beta$-Bisabolene & 1.506 & & & & & & 1.5 & & & & 0.4 & $a, b, c$ \\
\hline Selina-3,7(11)-diene & 1.547 & & & & & & & & 1.1 & & & $a, b$ \\
\hline Spathulenol & 1.578 & & & & & & & & 0.5 & & & $a, b, c$ \\
\hline Caryophyllene oxide & 1.583 & & & & 1.8 & 0.5 & 0.2 & & 0.4 & 0.7 & & $a, b$ \\
\hline Total & & 95.2 & 99.5 & 96.8 & 94.0 & 98.9 & 96.7 & 99.7 & 91.6 & 98.4 & 98.5 & \\
\hline
\end{tabular}

Compounds are listed in order of elution from an HP-5MS column (RI, Kovats Indices calculated against C8 to C24 n-alkanes on the HP-5MS column, other abbreviations as in Table 1). a, Rl comparison; b, MS comparison; c, Authentic samples comparison.

TABLE 3 | Mean number ( \pm S.E.) of Aedes albopictus landings on the uncovered area of the glove in $5 \mathrm{~min}$ and comparison with the standard DEET and the control (dichloromethane, DCM) after using different essential oils.

\begin{tabular}{|c|c|c|c|}
\hline Code & Mean number $( \pm$ S.E.) of landings $/ 5 \mathrm{~min}$ & $P_{\text {DEET }}$ & $P_{\text {DCM }}$ \\
\hline $\mathrm{RC}$ & $11.13 \pm 2.65$ & $0.0003^{*}$ & $0.0008^{*}$ \\
\hline ET & $0.88 \pm 0.74$ & 0.1441 & $0.0006^{\star}$ \\
\hline $\mathrm{ETa}$ & $0.13 \pm 0.13$ & 0.3173 & $0.0005^{\star}$ \\
\hline SF & $0 \pm 0$ & 1 & $0.0003^{\star}$ \\
\hline $\mathrm{TC}$ & $0 \pm 0$ & 0.3173 & $0.0005^{\star}$ \\
\hline ○० & $0 \pm 0$ & 1 & $0.0003^{\star}$ \\
\hline FV & $3.5 \pm 1.65$ & $0.0008^{*}$ & $0.0107^{\star}$ \\
\hline VA & $1.25 \pm 0.59$ & $0.0103^{\star}$ & $0.0007^{\star}$ \\
\hline ST & $0 \pm 0$ & 1 & $0.0003^{\star}$ \\
\hline DEET & $0 \pm 0$ & - & - \\
\hline DCM & $56 \pm 4$ & - & - \\
\hline
\end{tabular}

*Indicates significant difference following Mann-Whitney U-test pair-wise comparison.

Fringed Rue EO is the only one tested as a repellent against Ae. albopictus (Ali et al., 2013; Conti et al., 2013), and in both cases, it was found efficient.

\section{Larvicidal Bioassay}

Based on our previous studies (Giatropoulos et al., 2012) a discriminate dose of $29 \mathrm{mg} / \mathrm{L}$ solution of the material to test was employed for our screening bioassays. The mortality rates of the essential oils tested were arbitrarily classified to "low," "moderate," and "very good" for those ranging between $0-50 \%$, $50-80 \%$, and $80-100 \%$, respectively. The EOs larvicidal screening revealed that Conehead Thyme and Rigani were able to achieve $100 \%$ Ae. albopictus larval mortality. Along with these two EOs may be categorized also the one retrieved from Savory, which exhibited a larval mortality rate of $96 \%$. The second group of EOs, which presented high toxicity for mosquito larvae, included Fennel with $80 \%$ mortality rate, Fringed Rue with $75 \%$, and Cortuk through acidic distillation with $66 \%$. Finally, a third group of EOs, retrieved from Cortuk (conventional distillation), Monk's Pepper, and Greek Sage exhibited moderate to minimal activity with respective mortality rates 44,14 , and $2 \%$. The larvicidal bioassay results are presented cumulatively in Table 4. Cortuk and Conehead Thyme EOs had never been assessed before with respect to arthropod related bioactivities. Conehead
TABLE 4 | Aedes albopictus larvae mortality rate ( \pm S.E.) by several EOs, $24 \mathrm{~h}$ after exposure.

\begin{tabular}{lcl}
\hline Code & Mean percentage ( \pm S.E.) of dead larvae* & Classification \\
\hline RC & $75.00( \pm 4.18) \mathrm{c}$ & Moderate \\
ET & $42( \pm 2) \mathrm{d}$ & Low \\
ETa & $66( \pm 4) \mathrm{c}$ & Moderate \\
SF & $2( \pm 2) \mathrm{ef}$ & Low \\
TC & $100( \pm 0) \mathrm{a}$ & Very good \\
OO & $100( \pm 0) \mathrm{a}$ & Very good \\
FV & $80.00( \pm 8.37) \mathrm{bc}$ & Very good \\
VA & $14.00( \pm 6.78) \mathrm{e}$ & Low \\
ST & $96( \pm 4) \mathrm{ab}$ & Very good \\
DMSO & $0( \pm 0) \mathrm{f}$ & - \\
\hline
\end{tabular}

A discriminate dose of $29 \mathrm{mg} / \mathrm{L}$ was used and the mortality rates of each tested $E O$ were classified to "low," "moderate," and "very good" (mortality rates ranged between 0 and $50 \%, 50$ and $80 \%$ and 80 and $100 \%$, respectively).

*Means in a column followed by the same letter are not significantly different $(P \geq 0.05)$, Mann- Whitney U-test.

Thyme EO biocide potentials are argued through its fungicide and nematicide properties (Saoud et al., 2010), antiparasitic (Machado et al., 2010), and antibacterial (Karampoula et al., 2016) activities, but mostly through its lipoxygenase and acetylcholinesterase inhibition evidence (Carrasco et al., 2016). Greek Sage, Rigani, Monk's Pepper, and Savory EOs present larvicidal activity against various arthropods, but not against Aedes sp. mosquitoes. Specifically Greek Sage has displayed moderate to low activity against $C x$. pipiens (Koliopoulos et al., 2010). Rigani EO bioactivities were reviewed by Tepe (Tepe et al., 2016), whom recorded its potentials as Cx. pipiens larvicide. Monk's Pepper was also tested and found of low efficacy against Cx. pipiens larvae (Cetin et al., 2011). A special reference is reserved for Savory $\mathrm{EO}$ as control agent against $C x$. pipiens biotype molestus (Michaelakis et al., 2007), and Anopheles gambiae (Dellagli et al., 2012).

Fennel and Fringed Rue EOs have resulted efficient larvicidals against Ae. albopictus; Conti et al. (2010), reported a higher toxicity for Fennel EO than that reported here and this may be explained by the EO's different composition. Benelli et al. (2014) in a comparative test of 10 EOs confirmed the herein detected activity of both Fennel and Rue indicating that the last 


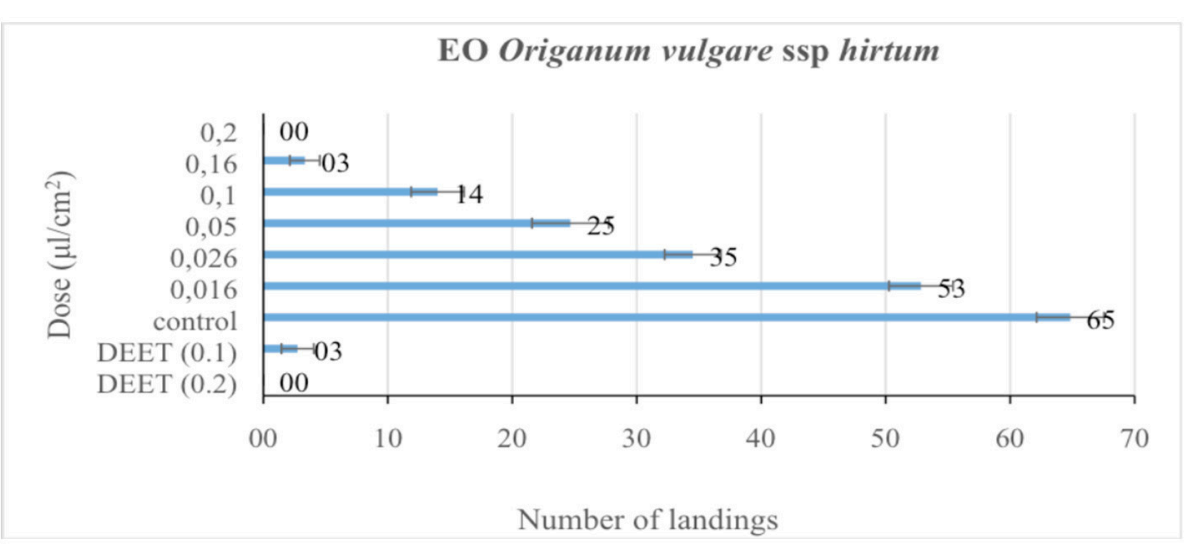

FIGURE 1 | Repellent activity of the oregano EO as mean number of landings ( \pm SE) determined under laboratory conditions. Doses are expressed as $\mu \mathrm{L} / \mathrm{cm}$. DEET was used as the positive control in two doses, 0.1 and $0.2 \mu \mathrm{L} / \mathrm{cm}$ for $5 \mathrm{~min}$. (Means in a column followed by the same letter are not significantly different $(P \geq 0.05$ ), Mann-Whitney U-test).

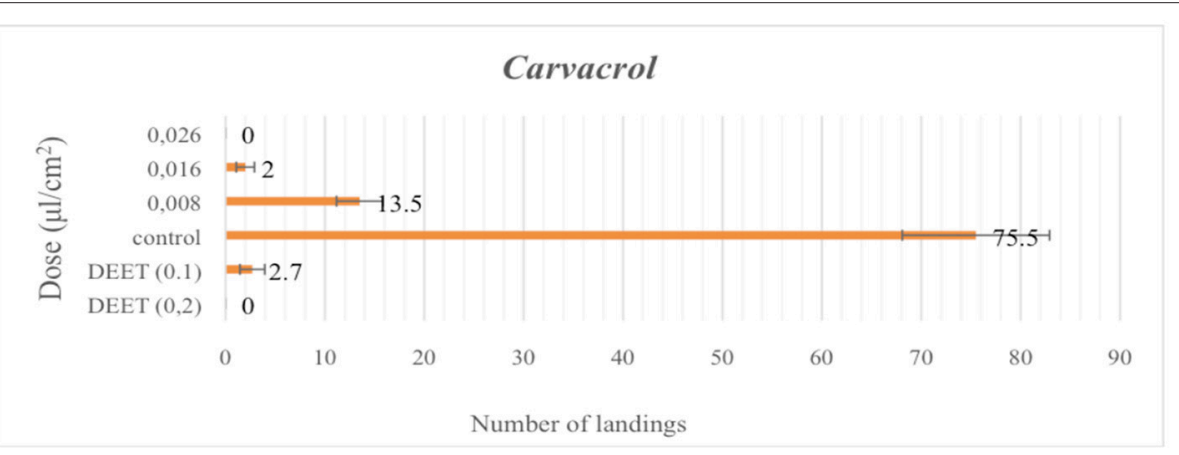

FIGURE 2 | Repellent activity of carvacrol as mean number of landings ( $\pm \mathrm{SE}$ ) determined under laboratory conditions. Doses are expressed as $\mu \mathrm{L} / \mathrm{cm}$. DEET was used as the positive control in two doses, 0.1 and $0.2 \mu \mathrm{lcm}^{-2}$ for $5 \mathrm{~min}$. (Means in a column followed by the same letter are not significantly different $(P \geq 0.05$ ), Mann-Whitney U-test).

outperformed all other EOs a result consistent with previous dedicated studies of Fringed Rue EO against both the Ae. albopictus (Conti et al., 2013), and Ae. aegypti (Ali et al., 2013).

\section{Up Scale}

\section{Dose Response and Formulation}

The repellent efficacies of the carvacrol and Oregano EO are shown in Figures 1, 2 highlighting both as very efficient repellents with activities comparable to DEET. At "high" dose $\left(2 \mu \mathrm{L} / \mathrm{cm}^{2}\right)$ EOs' repellent activity was "like-DEET" and when tested at "low" dose $\left(1 \mu \mathrm{L} / \mathrm{cm}^{2}\right)$ the activity was moderate $(>20$ landings). On the contrary, carvacrol resulted in a $100 \%$ repellent (zero landings) in a dose almost 10 -fold-lower to DETT $(0,026$ $\mu \mathrm{L} / \mathrm{cm}^{2}$ ) (Figure 2).

These results are in accordance with previous studies establishing the high level of protection exhibited by Carvacrol against Ae. Albopictus, in 5-fold-lower doses to DEET (Giatropoulos et al., 2018) and An. Gambiae (Kröber et al., 2018). Their respective larvicidal bioassays results are summarized in Table 5, verifying that the specific EO displays
TABLE 5 | LC 50 and LC90 values for Origanum vulgare ssp hirtum EO (OVk) and its major component, carvacrol, against third to fourth instar larvae of $A e$. albopictus.

\begin{tabular}{|c|c|c|c|c|c|}
\hline Active ingredient & Slope $( \pm$ SE) & $\begin{array}{c}\mathrm{LC}_{50} \\
(95 \% \mathrm{CL})^{\mathrm{a}}\end{array}$ & $\begin{array}{c}\mathrm{LC}_{90} \\
(95 \% \mathrm{CL})^{\mathrm{a}}\end{array}$ & $x^{2 b}$ & $d f$ \\
\hline OVk & $4.405( \pm 0.460)$ & $\begin{array}{c}30.1 \\
(27.4-32.7)\end{array}$ & $\begin{array}{c}58.7 \\
(51.6-70.5)\end{array}$ & 10.911 & 13 \\
\hline Carvacrol & $3.426( \pm 0.332)$ & $\begin{array}{c}13.1 \\
(11.1-15.2)\end{array}$ & $\begin{array}{c}31.1 \\
(25.3-43.2)\end{array}$ & $29.346^{b}$ & 16 \\
\hline
\end{tabular}

${ }^{a} L C$ values are expressed in $\mathrm{mg} / \mathrm{L}$, and they are considered significantly different when $95 \%$ CL fail to overlap.

${ }^{b}$ Since goodness-of-fit test is significant $(P<0.05)$, a heterogeneity factor is used in the calculation of $C L$.

an average $\mathrm{LC}_{90}$ value of $58.74(51.60-70.53) \mathrm{mg} / \mathrm{L}$, while the corresponding average $\mathrm{LC}_{90}$ value for pure Carvacrol is 31.08 (25.29-43.15) mg/L.

\section{Non-target Toxicity Bioassay}

The toxicities of Oregano EO and Carvacrol were also determined against the non-target aquatic species Macrocyclops 
TABLE 6 | LC 50 and LC90 values for Origanum vulgare ssp hirtum EO (OVk) and the its major component, carvacrol, against Macrocyclops albidus.

\begin{tabular}{lccccc}
\hline Active ingredient & Slope $( \pm$ SE) & $\begin{array}{c}\mathbf{L C}_{\mathbf{5 0}} \\
(\mathbf{9 5} \mathbf{\%} \mathbf{C L})^{\mathbf{a}}\end{array}$ & $\begin{array}{c}\mathbf{L C}_{\mathbf{9 0}} \\
(\mathbf{9 5 \%} \mathbf{C L})^{\mathbf{a}}\end{array}$ & $\mathbf{x}^{\mathbf{2}}$ & $\mathbf{d f}$ \\
\hline OVk & $3.386( \pm 0.351)$ & $\begin{array}{c}5.5 \\
(3.5-8.6)\end{array}$ & $\begin{array}{c}12.8 \\
(8.0-38.1)\end{array}$ & 74.620 & 10 \\
Carvacrol & $3.337( \pm 0.349)$ & 5.3 & 13.3 & 44.065 & 10 \\
& & $(3.1-11.6)$ & $(7.5-87.2)$ & &
\end{tabular}

a $L C$ values are expressed in $\mathrm{mg} / \mathrm{L}$ and they are considered significantly different when 95\% CL fail to overlap.

albidus. This species is widely present in European natural water bodies and recently was proposed as a possible biocontrol agent against Ae. albopictus in artificial breeding sites (Mulla et al., 1971). Results indicated (Table 6) that M. albidus adults are highly sensitive to both investigated products, displaying lower LC $_{90}$ values as compared to those observed for Ae. albopictus. These results clearly indicate that any use of these two agents as larvicidal is not feasible when predator's biocontrol programs are implemented.

\section{Field Assessment}

\section{Spatial Repellence}

The spatial repellent efficacy of the oregano EO in the form of water-based solution sprayed in a green urban area with high density of Ae. albopictus was also evaluated. In this respect, the capacity of the product to divert Ae. albopictus females out of the treated area was measured at day 1 and 2 up to day 3 after treatment. No adverse effects on the vegetation were observed.

The repellent efficacy measured just after treatment (day 0) was very low (\% reduction number female collected in the treated area compared to the control area was $32.5 \%$ ) and increased to $86.4 \%$ and $81.25 \%$ at day 1 and 2 post-treatment respectively. At day 3 post-treatment the reduction of females was determined as $69.67 \%$ (Table 7). The spatial repellency strategy to protect specific target areas from invasive mosquitoes has been recently proposed (Alten et al., 2003; Dame et al., 2014) as a possible mosquito control technology. Due to environmental concern, the spatial repellency approach can be accepted only in cases that products with completely safe profile, such as EOs, will be available.

\section{Catch Basin Repellent and Larvicidal Application}

Finally, a field test was performed in order to evaluate the potency of the oregano $\mathrm{EO}$ as both larvicidal and repellent against mosquitoes. The field trial was implemented during the period July 13-August 3 in catch basins, which constitute one of their most common breeding sites and therefore are regularly submitted to larval control. Application of the EO in breeding sites probably results in the simultaneous appearance of the following two main effects: the direct toxicity of the product against the breeding larvae and the repellent activity on the egglaying females. These two effects cannot be distinguished in our field assessment and are therefore cumulated in the observed data (Figure 3). During the field trials period, the water temperature inside the catch basins was $30.1 \pm 1.4^{\circ} \mathrm{C}$ (minimum $27^{\circ} \mathrm{C}$ and
TABLE 7 | Number of Aedes albopictus females collected with HLC during the field trial.

\begin{tabular}{llcccc}
\hline Time & Product & N & Mean & SD & Repellent efficacy (\%) \\
\hline pre-treat. & OVk & 2 & 20.00 & 7.07 & \\
& Control & 2 & 3.50 & 3.54 & 32.50 \\
day 0 & OVk & 2 & 13.50 & 3.54 & \\
& Control & 2 & 4.50 & 2.12 & 86.39 \\
day 1 & OVk & 2 & 10.50 & 2.12 & \\
post-treat & Control & 2 & 13.50 & 2.12 & 81.25 \\
day 2 & OVk & 2 & 7.50 & 2.12 & \multirow{2}{*}{69.67} \\
post-treat & Control & 2 & 7.00 & 2.83 & \\
day 3 & OVk & 2 & 13.00 & 4.24 & \\
post-treat & Control & 2 & 7.50 & 0.71 & \\
\multicolumn{2}{c}{ All Groups } & 20 & 10.05 & 5.50 & \\
\hline
\end{tabular}

Repellent efficacy calculated according to Mulla's formula (see text for more details).

maximum $33^{\circ} \mathrm{C}$ ), and along the trial period, one rainy event $(15.2 \mathrm{~mm})$ was registered at the Sant' Agata Bolognese weather station located $1.7 \mathrm{Km}$ from the study area.

In the treated catch basins, the larval mortality ( $C x$. pipiens \& Ae. albopictus) was $100 \%$ at days 2 and 7 post-treatment for both products tested (Table 8 ). At day 14 of post-treatment, the observed mortality was still $100 \%$ against $C x$. pipiens, for those treated with the oregano EO per se but some $C x$. pipiens larvae were detected in the catch basins treated with the emulsified EO. In respect the presence of Ae. albopictus, the presence of some larvae was detected the same day (14 post-treatment) in catch basins treated with both crude and emulsified EO but mortality was still high (Table 8). Finally, at day 21 of post-treatment no significant differences were observed between treated and control catch basins.

The observed data dynamics advocate the conclusion that the repellent effect of EO on the egg-laying females is not prolonged after 2 weeks. By checking the specific effect of the product against $C x$. pipiens and Ae. albopictus it seems that the products have slightly better activity against $C x$. pipiens. The emulsifier addition (TWEEN ${ }^{\circledR} 20$ ) did not affect the EO's efficacy.

\section{CONCLUSIONS}

The present study was aiming to develop a streamlined process for the valorization of bio-prospecting results in product development. As subjects of bio-prospecting were defined Mediterranean culinary plants, while as valorization target was selected the Ae. albopictus control. Of increased significance was the transition between experimentation phases that presented three major challenges; first, the identification of a broadly available CREO as indicated by the bio-prospecting results; second, the delineation of the suggested concentration in order to assure efficacy and environmental safety; third, the selection of a CREO formulation that would facilitate field application. Our results present for the first time the repellent properties of Conehead Thyme, Cortuk, Savory, Greek Sage, Monk's Pepper, and Fennel EOs against Ae. albopictus, as well as the larvicidal 


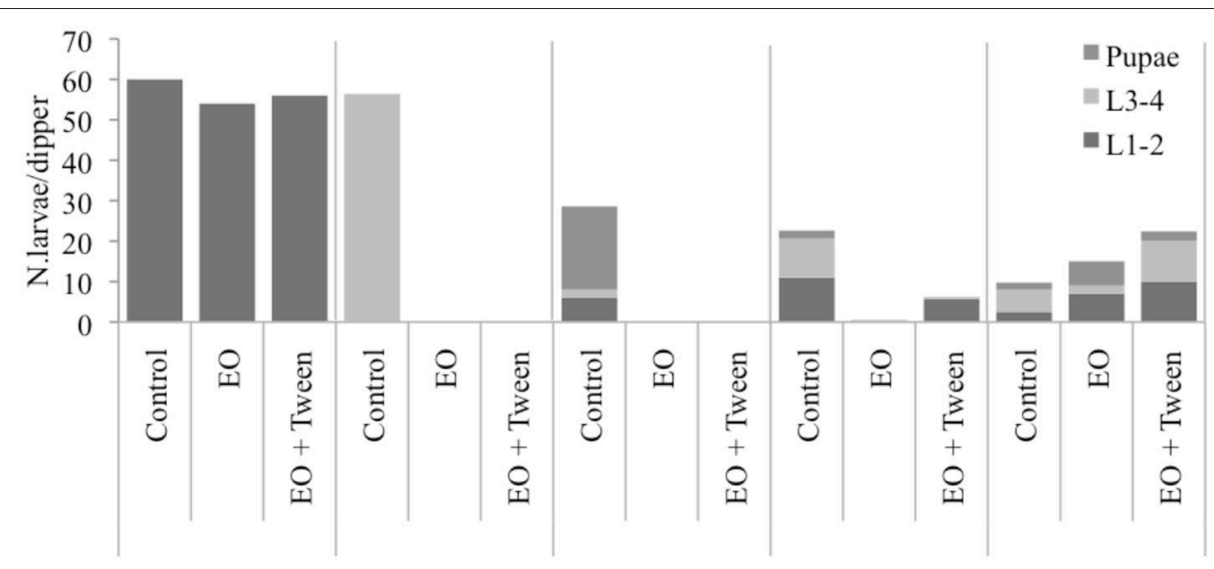

FIGURE 3 | Pre-imaginal mosquito population as sampled in experimental catch basins (Culex pipiens + Aedes albopictus, 22 post treatment days) in Crevalcore, Italy.

TABLE 8 | Mean number of Culex pipiens and Aedes albopictus larvae $\left(L_{1}-L_{2}-L_{3}-L_{4}\right)$ and pupae collected per aquatic net per road drain.

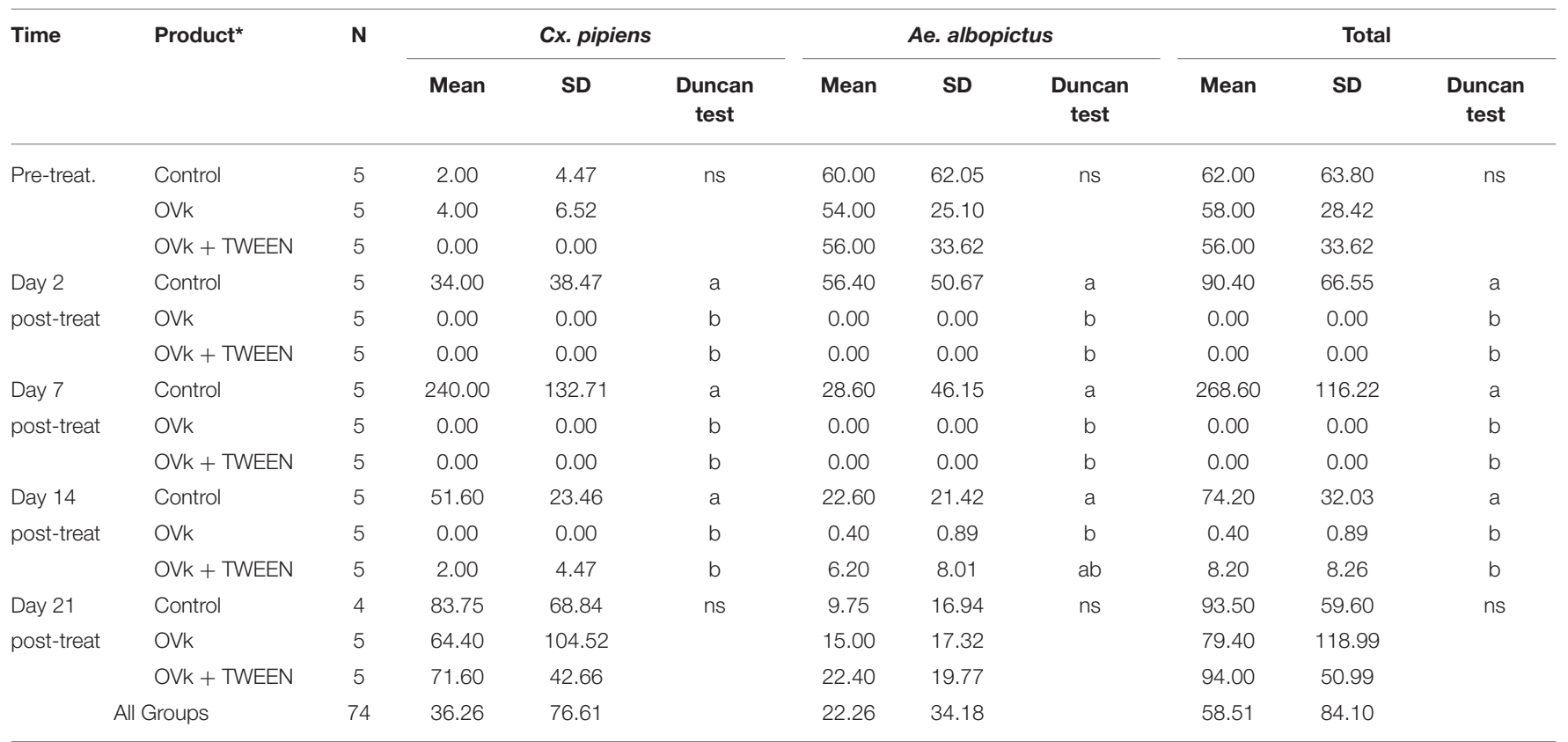

Catch basins treated with:"OVk": oregano EO; "OVk+TWEEN": oregano EO+ TWEEN ${ }^{\circledR} 20$ +water; "Control": untreated catch basins.

properties of Cortuk and Conehead Thyme EOs against the same target. The results obtained through field tests indicated that the emulsified CREO might be considered as a potent Ae. albopictus larvicidal and/or repellent agent. In summary, we believe that our approach successfully addressed the identified challenges and represents a methodological example for the exploitation of EOs as mosquito control agents, which may be of interest by relevant industries.

\section{AUTHOR CONTRIBUTIONS}

EE was responsible for the initial bioprospecting conceptualization including the collection, identification and documentation of the herbal material; the field assessment formulation composition; and the manuscript drafting. RB was responsible for the field assessment conceptualization and implementation supervision. GB was responsible for the laboratory bioassays including both initial bioprospecting and dose-response experiments. AM was responsible for the overall laboratory experimentation design and implementation supervision of the larvicidal and repellent bioassays. MC was responsible for the implementation of the spatial repellent experimentation. RV was responsible for the implementation of the combined repellent and larvicidal experimentation. DP was responsible for the processing of the raw bioassay results. AP was responsible for the processing of the raw field assessment results and the ecotoxicity bioassay. V-NK was responsible for 
the essential oils isolation and chemical characterization. SH was responsible for the overall research conceptualization and the manuscript finalization.

\section{ACKNOWLEDGMENTS}

This research has been co-financed by the European Union (EU Environmental Funding Programme LIFE+ Environment

\section{REFERENCES}

Ali, A., Demirci, B., Kiyan, H. T., Bernier, U. R., Tsikolia, M., Wedge, D. E., et al. (2013). Biting deterrence, repellency, and larvicidal activity of Ruta chalepensis (Sapindales: Rutaceae) essential oil and its major individual constituents against mosquitoes. J. Med. Entomol. 50, 1267-1274. doi: 10.1603/ME12177

Alten, B., Caglar, S. S., Simsek, F. M., Kaynas, S., and Perich, M. J. (2003). Field evaluation of an area repellent system (Thermacell) against Phlebotomus papatasi (Diptera: Psychodidae) and Ochlerotatus caspius (Diptera: Culicidae) in Sanliurfa Province, Turkey. J. Med. Entomol. 40, 930-934. doi: 10.1603/0022-2585-40.6.930

Baser, K. H. C., Erdemgil, F. Z., and Ozek, T. (1994). Essential Oil of Echinophora tenuifolia L. subsp. sibthorpiana (Guss.) Tutin. J. Ess. Oil Res. 6, 399-400. doi: 10.1080/10412905.1994.9698406

Benelli, G., Canale., A., and Conti, B. (2014). Eco-friendly control strategies against the Asian tiger mosquito, Aedes albopictus (Diptera: Culicidae): repellency and toxic activity of plant essential oils and extracts. PharmacologyOnLine 1, 44-51.

Carrasco, A., Perez, E., Cutillas, A.-B., Martinez-Gutierrez, R., Tomas, V., and Tudela, J. (2016). Origanum vulgare and thymbra capitata essential oils from Spain: determination of aromatic profile and bioactivities. Nat. Prod. Commun. 11, 113-120.

Carroll, J. F., Demirci, B., Kramer, M., Bernier, U. R., Agramonte, N. M., Baser, K. H. C., et al. (2017). Repellency of the Origanum onites L. essential oil and constituents to the lone star tick and yellow fever mosquito. Nat. Prod. Res. 31, 2192-2197. doi: 10.1080/14786419.2017.1280485

Cetin, H., Yanikoglu., A., and Cilek, J. E. (2011). Larvicidal activity of selected plant hydrodistillate extracts against the house mosquito, Culex pipiens, a West Nile virus vector. Parasitol. Res. 108, 943-948. doi: 10.1007/s00436-010-2136-Z

Chellappandian, M., Senthil-Nathan, S., Vasantha Srinivasan, P., Ponsankar, A., Thanigaivel, A., Edwin, E., et al. (2018). Botanical essential oils as mosquitocides and repellents against dengue vectors of human disease: phytochemical review. Environ. Int. 113, 214-230. doi: 10.1016/j.envint.2017.12.038

Choochote, W., Chaithong, U., Kamsuk, K., Jitpakdi, A., Tuetun, B., Champakaew, D., et al. (2007). Repellent activity of selected essential oils against Aedes aegypti. Fitoterapia 78, 359-364. doi: 10.1016/j.fitote.2007.02.006

Conti, B., Canale, A., Bertoli, A., Gozzini, F., and Pistelli, L. (2010). Essential oil composition and larvicidal activity of six Mediterranean aromatic plants against the mosquito Aedes albopictus (Diptera: Culicidae). Parasitol. Res. 107, 1455-1461. doi: 10.1007/s00436-010-2018-4

Conti, B., Leonardi, M., Pistelli, L., Profeti, R., Ouerghemmi, I., and Benelli, G. (2013). Larvicidal and repellent activity of essential oils from wild and cultivated Ruta chalepensis L. (Rutaceae) against Aedes albopictus Skuse (Diptera: Culicidae), an arbovirus vector. Parasitol. Res. 112, 991-999. doi: 10.1007/s00436-012-3221-2

Dame, D. A., Meisch, M. V., Lewis, C. N., Kline, D. L., and Clark, G. G. (2014). Field evaluation of four spatial repellent devices against Arkansas rice-land mosquitoes. J. Am. Mosquito Control Assoc. 30, 31-36. doi: 10.2987/13-6379.1

Dellagli, M., Sanna, C., Rubiolo, P., Basilico, N., Colombo, E., Scaltrito, M. M., et al. (2012). Anti-plasmodial and insecticidal activities of the essential oils of aromatic plants growing in the Mediterranean area. Malaria J. 11:219. doi: 10.1186/1475-2875-11-219

Economou, G., Panagopoulos, G., Karamanos, A., Tarantilis, P., Kalivas, D., and Kotoulas, D. (2014). An assessment of the behavior of carvacrol - rich wild
Policy and Governance) along with Greek national funds and Emilia-Romagna Regional funds, through the LIFE CONOPS project (http://www.conops.gr) Development \& demonstration of management plans against-the climate change enhancedinvasive mosquitoes in S. Europe (LIFE12 ENV/GR/000466). The funders had no role in study design, data collection and analysis, decision to publish, or preparation of the manuscript. We also thank the Municipalities of Bologna and Crevalcore for kindly hosting our field trials.

Lamiaceae species from the eastern Aegean under cultivation in two different environments. Ind. Crops Prod. 54, 62-69. doi: 10.1016/j.indcrop.2013.12.044

Enayati, A., and Hemingway, J. (2010). Malaria management: past, present, and future. Ann. Rev. Entomol. 55, 569-591. doi: 10.1146/annurev-ento-112408-085423

Evergetis, E., Michaelakis, A., and Haroutounian, S. A. (2012). "Essential oils of Umbelliferae family taxa as potent agents for Mosquito Control," in Integrated Pest Management and Pest Control, eds M. L. Larramendy, and S. Soloneski (Rijeka: InTech Publishers), 613-637.

Evergetis, E., Michaelakis, A., Papachristos, D. P., Badieritakis, E., KapsaskiKanelli, V. N., and Haroutounian, S. A. (2016). Seasonal variation and bioactivity fluctuation of two Juniperus sp. essential oils against Aedes (Stegomyia) albopictus (Skuse 1894). Parasitol. Res. 115, 2175-2183. doi: 10.1007/s00436-016-4959-8

Giatropoulos, A., Kimbaris, A., Michaelakis, A., Papachristos, D. P., Polissiou, M. G., and Emmanouel, N. (2018). Chemical composition and assessment of larvicidal and repellent capacity of 14 Lamiaceae essential oils against Aedes albopictus. Parasitol. Res. 117, 1953-1964. doi: 10.1007/s00436-018-5 892-9

Giatropoulos, A., Papachristos, D. P., Kimbaris, A., Koliopoulos, G., Polissiou, M. G., Emmanouel, N., et al. (2012). Evaluation of bioefficacy of three Citrus essential oils against the dengue vector Aedes albopictus (Diptera: Culicidae) in correlation to their components enantiomeric distribution. Parasitol. Res. 111, 2253-2263. doi: 10.1007/s00436-012-3074-8

Govere, J., and Durrheim, D. (2015). “Techniques for evaluating repellents," in Insect Repellents: Principles, Methods and Uses, eds Debboun, M., Frances, S. P., and Strickman, D (Boca Raton: CRC Press), 147-159.

Karampoula, F., Giaouris, E., Deschamps, J., Doulgeraki, A. I., Nychas, G. J., and Dubois-Brissonnet, F. (2016). Hydrosol of Thymbra capitata is a highly efficient biocide against Salmonella enterica serovar Typhimurium biofilms. Appl. Environ. Microbiol. 82, 5309-5319. doi: 10.1128/AEM.013 51-16

Kim, D., Kim, S., and Chang, K., Ahn, Y. (2002). Repellent activity of constituents identified in Foeniculum vulgare fruit against Aedes aegypti (diptera: Culicidae). J. Agric. Food Chem. 50, 6993-6996. doi: 10.1021/jf020504b

Koliopoulos, G., Pitarokili, D., Kioulos, E., Michaelakis, A., and Tzakou, O. (2010). Chemical composition and larvicidal evaluation of Mentha, Salvia, and Melissa essential oils against the West Nile virus mosquito Culex pipiens. Parasitol. Res. 107, 327-335. doi: 10.1007/s00436-010-1865-3

Kongkaew, C., Sakunrag, I., Chaiyakunapruk, N., and Tawatsin, A. (2011). Effectiveness of citronella preparations in preventing mosquito bites: systematic review of controlled laboratory experimental studies. Trop. Med. Int. Health 16, 802-810. doi: 10.1111/j.1365-3156.2011.02781.x

Kröber, T., Koussis, K., Bourquin, M., Tsitoura, P., Konstantopoulou, M., Awolola, T. S., et al. (2018). Odorant-binding protein-based identification of natural spatial repellents for the African malaria mosquito Anopheles gambiae. Insect Biochem. Mol. Biol. 96, 36-50. doi: 10.1016/j.ibmb.2018.03.008

Kroeger, A., Lenhart, A., Ochoa, M., Villegas, E., Levy, M., Alexander, N., et al. (2006). Effective control of dengue vectors with curtains and water container covers treated with insecticide in Mexico and Venezuela: cluster randomised trials. Brit. Med. J. 332, 1247-1252. doi: 10.1136/bmj.332.7552.1247

Lees, R. S., Gilles, J. R. L., Hendrichs, J., Vreysen, M. J. B., and Bourtzis, K. (2015). Back to the future: the sterile insect technique against mosquito disease vectors. Curr. Opin. Insect Sci. 10, 156-162. doi: 10.1016/j.cois.2015.05.011 
Loh, P. Y., and Yap, H. H. (1989). Laboratory studies on the efficacy and sublethal effects of an insect growth regulator, pyriproxyfen (S-31183) against Aedes aegypti (Linnaeus). Trop. Biomed. 6, 7-12.

Machado, M., Sousa, M. D. C., Salgueiro, L., and Cavaleiro, C. (2010). Effects of essential oils on the growth of Giardia lamblia trophozoites. Nat. Prod. Comm. 5, 137-141.

Michaelakis, A., Theotokatos, S. A., Koliopoulos, G., and Chorianopoulos, N. G. (2007). Essential oils of Satureja species: insecticidal effect on Culex pipiens larvae (Diptera: Culicidae). Molecules 12, 2567-2578. doi: 10.3390/12122567

Morrison, A. C., Zielinski-Gutierrez, E., Scott, T. W., and Rosenberg, R. (2008). Defining challenges and proposing solutions for control of the virus vector Aedes aegypti. PLoS Med. 5:e68. doi: 10.1371/journal.pmed.0050068

Mulla, M. S., Norland, R. L., Fanara, D. M., Darwazeh, H. A., and McKean, D. W. (1971). Control of chironomid midges in recreational lakes. J. Econ. Entomol. 64, 300-307. doi: 10.1093/jee/64.1.300

Müller, G. C., Junnila, A., Butler, J., Kravchenko, V. D., Revay, E. E., Weiss, R. W., et al. (2009). Efficacy of the botanical repellents geraniol, linalool, and citronella against mosquitoes. J. Vector Ecol. 34, 2-8. doi: 10.1111/j.1948-7134.2009.00002.x

Perestrelo, R., Silva, C. L., Rodrigues, F., Caldeira, M., and Câmara, J. S. (2016). A powerful approach to explore the potential of medicinal plants as a natural source of odor and antioxidant compounds. J. Food Sci. Technol. 53, 132-144. doi: 10.1007/s13197-015-2022-x

Pires, M. M., Périco, E., Renner, S., and Sahlén, G. (2018). Predicting the effects of future climate change on the distribution of an endemic damselfly (Odonata, Coenagrionidae) in subtropical South American grasslands. J. Insect Conserv. 22, 309-319. doi: 10.1007/s10841-018-0063-y

Ramadass, M., and Thiagarajan, P. (2015). A review on melaleuca alternifolia (tea tree) oil. Int. J. of Pharma Bio Sci. 6, 655-661.

Rather, M. A., Dar, B. A., Sofi, S. N., Bhat, B. A., and Qurishi, M. A. (2016). Foeniculum vulgare: a comprehensive review of its traditional use, phytochemistry, pharmacology, and safety. Arab. J. Chem. 9, 1574-1583. doi: 10.1016/j.arabjc.2012.04.011

Sands, P., Mundaca-Shah, C., and Djau, V. J. (2016). The neglected dimension of global security- a framework for countering infectious-disease crises. New Engl. J. Med. 374, 1281-1287. doi: 10.1056/NEJMsr1600236

Saoud, I., Hamrouni, L., Hanana, M., Bouzid, S., and Khouja, M. L. (2010). Ethnobotanical and phytopharmacological notes on Coridothymus capitatus (L.) Reichenb. Fil. Phytother. 8, 370-373. doi: 10.1007/s10298-010-0592-3

Semmler, M., Abdel-Ghaffar, F., Al-Rasheid, K., and Mehlhorn, H. (2009). Nature helps: from research to products against blood-sucking arthropods. Parasitol. Res. 105, 1483-1487. doi: 10.1007/s00436-009-1634-3

Semmler, M., Abdel-Ghaffar, F., Schmidt, J., and Mehlhorn, H. (2014). Evaluation of biological and chemical insect repellents and their potential adverse effects. Parasitol. Res. 113, 185-188. doi: 10.1007/s00436-013-3641-7
Senatore, F., Porta, G. D., and Reverchon, E. (1996). Constituents of Vitex agnuscastus L. essential oils. Flavour Fragr. J. 11, 179-182.

Tepe, B., Cakir, A., and Tepe, A. S. (2016). Medicinal uses, phytochemistry, and pharmacology of Origanum onites (L.): a Review. Chem. Biodiv. 13, 504-520. doi: $10.1002 /$ cbdv.201500069

The Plant List (2013). version 1.1. Available online at: http://www.theplantlist.org/

Traboulsi, A. F., El-Haj, S., Tueni, M., Taoubi, K., Nader, N. A., and Mrad, A. (2005). Repellency and toxicity of aromatic plant extracts against the mosquito Culex pipiens molestus (Diptera: Culicidae). Pest Manag. Sci. 61, 597-604. doi: $10.1002 / \mathrm{ps} .1017$

Tutin, T. G., Heywood, V. H., Burges, N. A., Valentine, D. H., Walters, S. M., and Webb, D. A. (2013). Flora Europaea, 5th Vol. (Cambridge: Cambridge University Press).

Veronesi, R., Carrieri, M., Maccagnani, B., Maini, S., and Bellini, R. (2015). Macrocyclops albidus (Copepoda: Cyclopidae) for the biocontrol of Aedes albopictus and Culex pipiens in Italy. J. Am. Mosquito Contr. Assoc. 31, 32-43. doi: $10.2987 / 13-6381.1$

Vogel, G. (2017). Where have all the insects gone? Science 356, 576-579. doi: $10.1126 /$ science.aal1160

WHO (2005). Guidelines for Laboratory and Field Testing of Mosquito Larvicides. Geneva: World Health Organization, 1-41. Ref: WHO/CDS/WHOPES/GCDPP/2005.11

WHO (2006) Indoor Residual Spraying. Use of Indoor Residual Spraying for Scaling Up Global Malaria Control and Elimination. Geneva: WHO Position Statement, World Health Organization.

WHO (2016). Zika Strategic Response Framework \& Joint Operations Plan. New York, NY: World Health Organization, 1-32.

Zhang, D., Zheng, X., Xi, Z., Bourtzis, K., and Gilles, J. R. (2015). Combining the sterile insect technique with the incompatible insect technique: i-impact of Wolbachia infection on the fitness of triple- and double-infected strains of Aedes albopictus. PLoS ONE 10:e0121126. doi: 10.1371/journal.pone.0121126

Conflict of Interest Statement: The authors declare that the research was conducted in the absence of any commercial or financial relationships that could be construed as a potential conflict of interest.

Copyright (C) 2018 Evergetis, Bellini, Balatsos, Michaelakis, Carrieri, Veronesi, Papachristos, Puggioli, Kapsaski-Kanelli and Haroutounian. This is an open-access article distributed under the terms of the Creative Commons Attribution License (CC $B Y)$. The use, distribution or reproduction in other forums is permitted, provided the original author(s) and the copyright owner(s) are credited and that the original publication in this journal is cited, in accordance with accepted academic practice. No use, distribution or reproduction is permitted which does not comply with these terms. 